\title{
SMART TEXTILE FOR BUILDING AND LIVING
}

\author{
Georgios Priniotakis ${ }^{1, *}$, Laetitia Marrot ${ }^{2}$, Urszula Stachewicz ${ }^{3}$, Aleksandra Krstic-Furundzic ${ }^{4}$, Enrico Venturini ${ }^{5}$, \\ Vaida Jonaitiene ${ }^{6}$
}

1 Industrial Design and Production Engineering Department, University of West Attica, 250 Thivon \& P. Ralli Street, Egaleo Postal code 12241, Athens, Greece

2 InnoRenew CoE, Renewable Materials Composites Group, Livade 6, 6310 Izola, Slovenia

3 Faculty of Metals Engineering and Industrial Computer Science, AGH University of Science and Technology, al. A. Mickiewicza 30, Kraków, Poland 4 Faculty of Architecture, University of Belgrade, Bulevar Kralja Aleksandra 73/II, Belgrade, Serbia

5 Next Technology Tecnotessile Società Nazionale di Ricerca r.l., Via del Gelso 13, 59100 Prato, Italy 6 Faculty of Mechanical Engineering and Design, Kaunas University of Technology, Studentu Street 56, Kaunas, Lithuania *Corresponding author: E-mail: gprin@uniwa.gr

\begin{abstract}
:
In construction, textiles can be used either for reinforcing the structure or for finishing design. When we talk about function, the interior is no less important than the exterior and architecture of the building. Thus using textiles to reinforce the structure of buildings, textiles often perform a desired function of reinforcing the "finish." Building textile materials include fibers that are mixed with concrete, fiberglass reinforcement meshes, insulators, etc. Textile architecture covers permanent tensile structures based on polyester or glass fiber fabrics, with polyvinyl chloride (PVC) or polytetrafluoroethylene (PTFE) coating and awnings generally supported by polyester or polyolefin fabrics, with or without coating, especially for gardening. All above topics are covered within this perspective with the experts from the group of smart textiles for building and living within COST Action CA17107 European Network to Connect Research and Innovation Efforts on Advanced Smart Textiles (CONTEXT) [1].
\end{abstract}

\section{Keywords:}

Smart textile, building, living, acoustic

\section{Introduction}

The European Green Rate Action Plan aims to reduce the energy sector's dependence on fossil fuels in a targeted way, currently by $>75 \%$. The EU's $\mathrm{CO}_{2}$ emissions come from energy production and its use, and European industry uses only $12 \%$ of its -recycled materials. In addition, as much as $40 \%$ Energy is used in buildings - most buildings in the EU are energy inefficient [1]. Both civil engineering and building industry are integral parts of the development of human society as they involve the planning, design, building, operation, and maintenance of infrastructure. The venturing of technical textiles or highperformance textiles in this sector has given a great impetus to the quality of construction [2].

Nature is an amazing source of inspiration for the design of thermal insulation strategies too, which are key for saving energy. In nature, thermal insulation structures, such as penguin feather and polar bear hair, are well developed; enabling the animals' survival in frigid waters. Thermal insulation is a great solution to reduce energy consumption by preventing heat gain or loss through the building envelope. Any reduction of unwanted temperature changes is decreasing the energy demand of heating and cooling systems. Incorporation of thermal insulation of every element under the thermal envelope such as walls, roofs, and floors or water heaters improves the thermal comfort at homes,

\section{Results and discussion}

\subsection{The challenges of textile materials in the building and} living sectors

In the building and living sectors, one of the main concepts that is being explored is the zero-energy building, which is based on the improvement of materials used, construction methods, and architectural design. In this scope the use of textile based materials, such as composite structures, can contribute in both the reduction of the amount of raw materials used and the reduction of energy consumption and this can be seen as a determinant factor to achieve this goal [3].

In particular, buildings should be technically innovative, safe, and durable. In architecture, textiles can be used in both exterior and interior design. Today's architectural challenges are to create exceptional buildings that are not only admirable for their exterior appearance but also function in an innovative and purposeful way, and most importantly, should meet the public requirements. An architect always faces the challenge of creating a whole from many different functions, shapes, materials, and sizes. Textiles offer variety in terms of material choice and the possibility of forms. Textiles play an important role in the interior spaces and daily activities of people, both functionally and esthetically. Textile materials are multi-materials (fibers or filaments making yarns, making woven, nonwoven, knitted, braided materials, making complexes, making 
products), with specific intrinsic property will be especially useful for all the application sectors: conformability. Mostly, textile is used in constructions; it is used for interior decoration of walls and this is utilized for both interior reinforcement and design. Rare fabrics or nets are used for reinforcing plaster, and fabrics can be glued onto pre-existing plaster and then sealed. This strengthens the interior finish of the wall—small cracks in the wall are not detectable from the outside. Fiberglass fabrics are often used for this purpose. Fabrics are also used for wall decoration and, in this case, are not hidden under another layer of construction material. Such wallpaper fabrics can be dyed, but the fabric structure still remains visible. Textile for building and living sectors provides many interesting technological solutions $[4,5]$.

Acoustics are also important in both public and residential spaces, especially in open-plan spaces where there is more noise. According to the World Green Building Council, noise can reduce employee productivity by $66 \%$ [6]. Acoustics can be improved with special finishing materials as well as with partitions that have good acoustic properties. "Acoustic comfort" increases work efficiency and improves the quality of rest (during breaks from work), so sound-absorbing materials are necessary in various public spaces.

Textiles for building with advanced functionalities:

- Photocatalytic action of materials/textiles to reduce pollutants (indoor/outdoor), antibacterial effect of titanium dioxide, combine fabrics made of optical fibers with applications in filtering/depolluting systems.

- Use of Polyvinylidene fluoride (PVDF) as a novel material for building applications, with new properties for textile structures (UV protection); use of piezoelectrical properties of PVDF in innovative energy production systems [7]; extrusion of PVDF filled with nanoparticles to enhance its performance [8].

a)
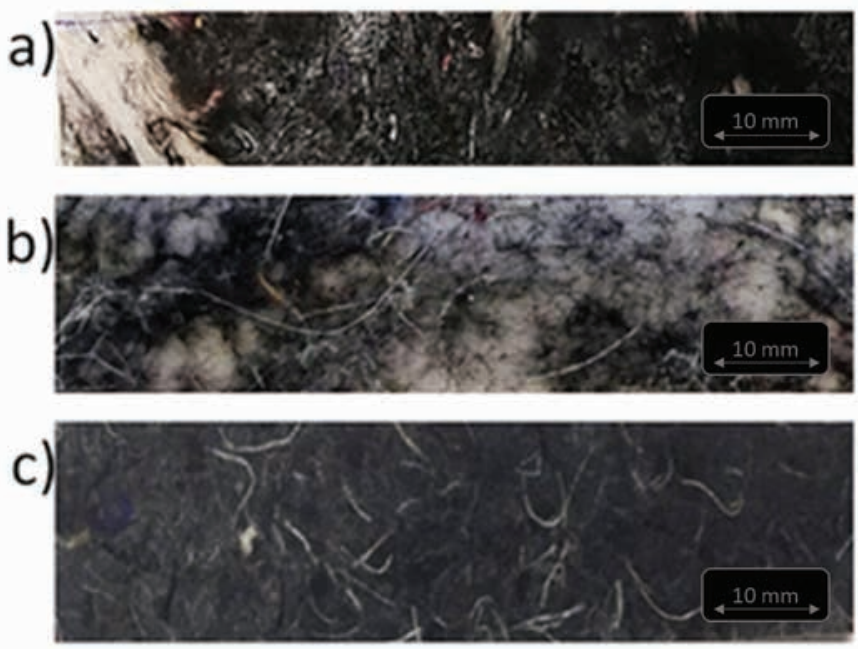

Figure 1. The polymer based textile and examples (a) showing the composite with dust and polylactic acid (PLA), (b) textile waste with PLA, and (c) Composite with nonwoven material from textile and PP waste.

\section{- Self-regulating systems.}

With the arrival of composites, easily transformable spaces allow us to change the functions of the premises (Figure 1). Acoustic panels made from textile waste reduce and divert sound, thus eliminating echo. Acoustic partitions made from recycled textile and plastic waste are lightweight, improve sound quality indoors, and can be easily moved from one place to another.

Textiles are also used in the production of building structures.

Concrete's ongoing popularity for developing new modern infrastructure all over the globe is due to its high compressive strength, durability, and low cost. However, the main drawbacks of concrete, when used in construction, are its brittleness and unreliable tensile strength. In the 1970 s textile materials emerged as an alternative solution to steel bars for concrete reinforcement [9]. Textile reinforced concrete does not require an additional concrete protective layer since the material itself is not prone to corrosion, unlike steel. This results in a significant reduction of material usage and cost. Textiles made of metallic, ceramic, synthetic polymers, inorganic or natural fibers have been considered for this purpose. By mixing various textile materials into concrete, it is possible to change the properties of the resulting material, such as stiffness, flexibility, etc. [10]. For example, when added to concrete, para-aramid fibers significantly increase their flexural strength [11]. Textile structures are the next generation of architecture. This property means comfort for ability to reach $3 D$ shapes with good mechanical properties for the composites industry, high thermal performance and an ability to adapt to external conditions with an outstanding and inclusive design for building and architecture sector.

Bioinspired materials are also used as thermal insulation materials in living and building sectors. Many animals and plants know how to preserve and store thermal energy. The thermal insulation properties are bioinspired by feather, hair, fur, or wool [12-15], which are all keratin-based materials. Keratin is one of the most studied structural proteins, and it is an important building block found in many natural materials, which display unique material properties. Most keratin-based materials are porous [16], which is a key construction strategy for lightweight materials with high mechanical strength. Feather is one of the most common light and aerodynamic structures that has been widely studied in terms of its mechanical properties [17, 18], super-hydrophobicity [19], and other properties such as acoustic attenuation [20]. For many animals, keeping a constant body temperature is the key to survival, which is achieved by covering the body with naturally porous insulating materials, see examples in Figure 2.

Penguin feather and polar bear hair prevent the penetration of cold seawater to the skin and play an insulating role. Both materials, penguin feather and polar bear hair, are keratin based but with different molecular arrangements. Hair is usually composed of alpha-keratin, with coiled-coil molecular structure whereas feathers are built out of beta-keratin sheets [21]. Although these structures are different, their microstructures 


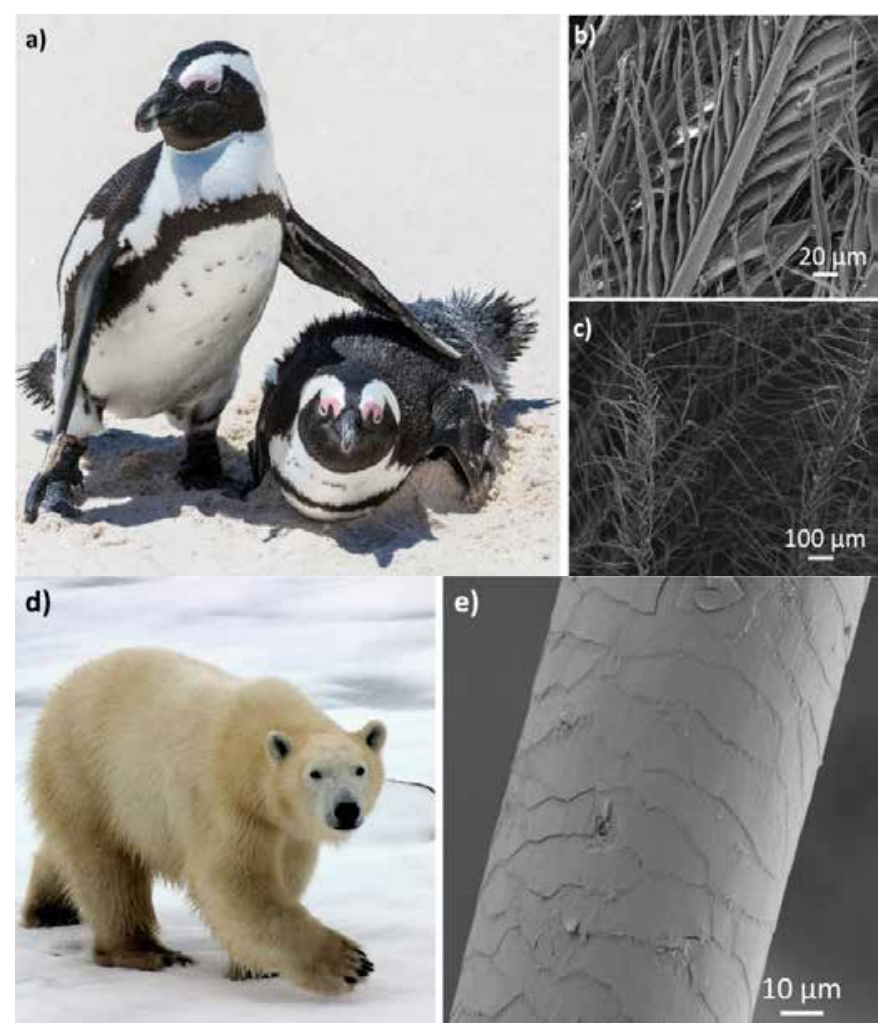

Figure 2. The examples of natural thermally insulating materials: (a) penguin , (b, c) feather micrographs, (d) polar bear hair, and (e) polar bear hair micrograph.

have many similarities such as interconnected porosity [22], which indicates the importance of porosity in adaptive thermal insulation, see Figure 3. One of the best examples is polar bear hair in which the porosity of hair helps them to convert sunlight energy into thermal energy through a photothermal conversion process [23]. The polar bear was the bioinspiration for synthetic materials with excellent UV absorption properties [15].

The use of textiles in the construction sector allows for a fast and high quality construction process, as the majority of building components are manufactured in factories and assembled on site. Reducing the number of construction processes carried out in site ensures faster construction and high quality [24].

Various materials are used for the facades of modern buildings__even textiles. Textile facades are popular all over the world because they are durable and resistant to UV rays and temperature fluctuations. In summer, a polymer-coated polyvinyl chloride (PVC) textile facade can protect a building from overheating. A new era in construction began when textiles were used to decorate the facades of buildings. The facade covered with a dedicated textile has been found to protect the building from overheating in the summer by block $30 \%$ of light, and further saves energy, suppresses the city noise, and provides privacy to those in the building [25]. This material can be used to cover windows, unattractive places in the building, to create new spaces and shapes, to give the building bright colors. The material can be printed on, and in the event of a change in the owner or user of the building, the material can be easily replaced with more appropriate color

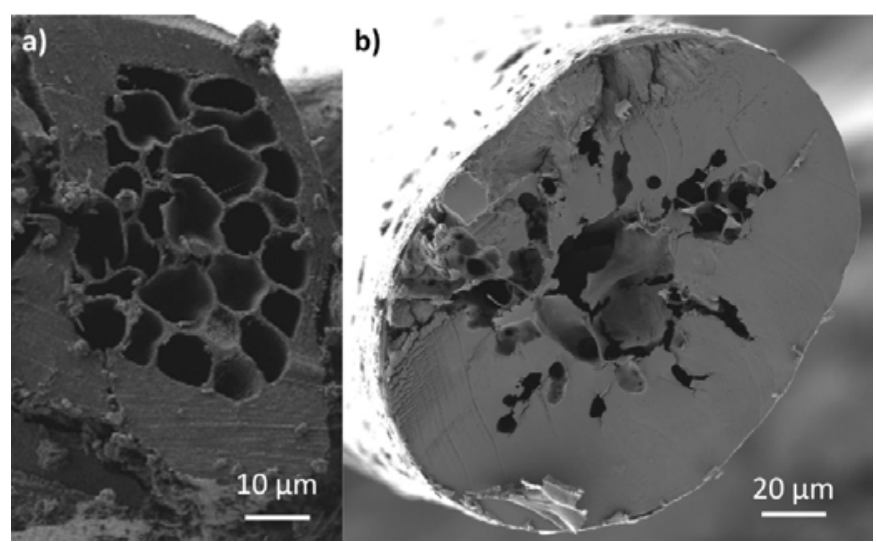

Figure 3. Cross-sectional scanning electron micrographs of (a) penguin feather and (b) polar bear hair.

and by exchanging the advertising signs and adapting to the corporate marketing vision. Textile facades are valued for their ease and quick installation. Because they weigh little, they do not require complex and expensive engineering solutions and, most importantly, such facades do not restrict the creativity of architects. After all, you can even print on the material. In addition, it is easy to change the color or patterns of such a facade. Concerning the building and living sectors, one of the main concepts that is being explored is the zero energy building, based on the improvement of materials used, construction methods and architectural design. In this scope the use of textile-based materials, such as composite structures, can contribute to both the reduction of the amount of raw materials and energy consumption. Facade textiles can be recycled by the manufacturer, and it is easy and quick to install. Due to its low weight, this textile does not require complex and extremely expensive engineering solutions. The mounting system is based on a patented, unique construction of aluminum profiles, consisting of dozens of different details to result.

\section{CONCLUSIONS}

The use of textiles in architecture has drawn immense attention and changed public opinion, leading to the abandonment of stereotypes, as they are in fact environmentally friendly, resistant to climate change, and are durable, long-lasting and prevent the spread of fire.

The main outcomes are: Create materials easy to incorporate with existing materials applied in building industry; Develop a light sensing structure based on polymeric fibers/fabric; Use of PVDF for buildings with new properties - producing energy; Textile waste-for the new textile structure, testing it for mechanical properties, SEM microstructure-develop a new product; Possible applications in buildings and urban environment to improve air quality; Introduction of multifunctionality, for example piezoelectric or UV resistant properties in the components, and in the process to develop fabric for construction; Composite model of waste with no chemical added. 


\section{ACKNOWLEDGMENTS}

This article is based upon work from working group Building and living participating in COST Action European Network to Connect Research and Innovation Efforts on Advanced Smart Textiles (CONTEXT) [COST Action 17107] supported by COST (European Cooperation in Science and Technology).

\section{References}

[1] A European Green Deal. Striving to be the first climateneutral continent, A European Green Deal | European Commission (europa.eu).

[2] El Hadi, H., Mansour, R., Priniotakis, G., Vassilliadis, S., Vasilakos, S., et al. (2018). Physico-chemical and mechanical characterization of jute fabrics for civil engineering applications. Journal of Computational Methods in Science and Engineering (JCMSE), 18, 129147, doi: 10.3233/JCM-180776.

[3] www.cost.eu. COST Action CA17107 European Network to Connect Research and Innovation Efforts on Advanced Smart Textiles (CONTEXT). Web site: http://www.contextcost. eu/overview/.

[4] Ollenhauer, C. (2011). Textiles in architecture: materials suppliers for building and construction. Silsden: Textile Media Services, Textile Media Services, 206.

[5] Echeverriaa, C. A., Pahlevani, F., Handoko, W., Jiangb, C. H., Doolan, C., et al. (2019). Engineered hybrid fibre reinforced composites for sound absorption building applications. Resources, Conservation \& Recycling, 143(2019), 1-14.

[6] World Green Building Council. Health, Wellbeing \& Productivity in Offices (The next chapter for green building). Web site: https://www.worldgbc.org/sites/ default/files/compressed_WorldGBC_Health_Wellbeing_ Productivity_Full_Report_Dbl_Med_Res_Fet__2015.pdf

[7] Szewczyk, P. K., Gradys, A., Kim, S. K., Persano, L., Marzec, M., et al. (2020). Enhanced Piezoelectricity of Electrospun Polyvinylidene fluoride fibers for energy harvesting. ACS Applied Materials \& Interfaces, 12(11), 13575-13583.

[8] Harstad, S., D'Souza, N., Soin, N., El-Gendy, A. A., Gupta, S., et al. (2017). Enhancement of b-phase in PVDF films embedded with ferromagnetic Gd5Si4 nanoparticles for piezoelectric energy harvesting. AIP Advances, 7, 056411.

[9] Curbach, M., et al. (1999). Sachstandbericht zum Einsatz von Textilien im Massivbau, Kurzber. AUS Bauforsch, 40(1).

[10] Brameshuber, M. (2006). Report 36: Textile Reinforced Concrete - State-of-the-Art Report of RILEM TC 201-TRC. RILEM Publications.
[11] Brückner, A., Ortlepp, R., Curbach, M. (2006). Textile reinforced concrete for strengthening in bending and shear. Materials and Structures, 39, 741-748.

[12] Taylor, J. R. E. (1986). Thermal Insulation of the down and Feathers of Pygoscelid Penguin Chicks and the Unique Properties of Penguin Feathers. Auk, 103(1), 160-168.

[13] Cui, Y., Gong, H., Wang, Y., Li, D., Bai, H. (2018). A thermally insulating textile inspired by polar bear hair. Advanced Materials, 30(14), 1706807.

[14] Simonis, P., Rattal, M., Oualim, E. M., Mouhse, A., Vigneron, J.-P. (2014). Radiative contribution to thermal conductance in animal furs and other woolly insulators. Optics Express, 22(2), 1941-1952.

[15] Jia, H., Guo, J., Zhu, J. (2017). Comparison of the photothermal energy conversion behavior of polar bear hair and wool of sheep. Journal of Bionic Engineering, 14(4), 616621.

[16] Rouse, J. G., Van Dyke, M. E. (2010). A review of keratinbased biomaterials for biomedical applications. Materials, 3(2), 999-1014.

[17] Bonser, R. H. C., Purslow, P. P. (1995). The youngsmodulus of feather keratin. Journal of Experimental Biology, 198(4), 1029-1033.

[18] Gupta, H. S., Stachewicz, U., Wagermaier, W., Roschger, P., Wagner, H. D., et al. (2006). Mechanical modulation at the lamellar level in osteonal bone. Journal of Materials Research, 21(8), 1913-1921.

[19] Bhushan, B., Jung, Y. C. (2011). Natural and biomimetic artificial surfaces for superhydrophobicity, self-cleaning, low adhesion, and drag reduction. Progress in Materials Science, 56(1), 1-108.

[20] Huda, S., Yang, Y. (2009). Feather fiber reinforced lightweight composites with good acoustic properties. Journal of Polymers and the Environment, 17(2), 131-142.

[21] Greenwold, M. J., Bao, W., Jarvis, E. D., Hu, H., Li, C., et al. (2014). Dynamic evolution of the alpha (alpha) and beta (beta) keratins has accompanied integument diversification and the adaptation of birds into novel lifestyles. BMC Evolutionary Biology, 14.

[22] Metwally, S., Comesaña, S. M., Zarzyka, M., Szewczyk, P. K., Karbowniczek, J. E., et al. (2019). Thermal insulation design bioinspired by microstructure study of penguin feather and polar bear hair. Acta Biomaterialia, 91, 270283.

[23] Jia, H., Zhu, J., Li, Z., Cheng, X., Guo, J. (2017). Design and optimization of a photo-thermal energy conversion model based on polar bear hair. Solar Energy Materials and Solar Cells, 159, 345-351.

[24] Liddell, T., Flore, I., Fontana, M., Romanova, N., Zamani, M. B., et al. (2019). Tension-actuated textiles for architectural applications. Proceedings of the TensiNet Symposium, 465-475. doi: 10.30448/ts2019.3245.20.

[25] Textile Fasades, Textile facades | i-tensing | Textile architecture | IASO (iasoglobal.com). 